\title{
Inducible morphological defense in Daphnia pulex: food quantity effects revised
}

\author{
Sandra Klintworth (iD $\cdot$ Eric von Elert $(\mathbb{D})$
}

Received: 21 June 2020/ Accepted: 24 October 2020/Published online: 7 November 2020

(C) The Author(s) 2020

\begin{abstract}
In aquatic systems, organisms largely rely on chemical cues to perceive information about the presence of predators or prey. Daphnia recognize the presence of the predatory larvae of Chaoborus via a chemical cue, emitted by the larvae, a so-called kairomone. Upon recognition, neckteeth, an alteration of the carapace, are induced in Daphnia that reduce predation rates of Chaoborus. Neckteeth induction was often reported to entail costs. In a previous study, food quantity affected the level of neckteeth induction, with stronger neckteeth induction at low food concentrations and weak induction at high food concentrations. However, reducing neckteeth induction at high food quantities seems to be maladaptive and not in accordance with the concept that inducible defenses are associated with costs.

Here, we hypothesized that weaker neckteeth induction at high food concentrations is caused by
\end{abstract}

Handling Editor: Télesphore Sime-Ngando

Electronic supplementary material The online version of this article (https://doi.org/10.1007/s10452-020-09809-2) contains supplementary material, which is available to authorized users.

S. Klintworth $(\bowtie) \cdot$ E. von Elert

Aquatic Chemical Ecology, Biocenter, University of Cologne, Zülpicher Straße 47 b, 50674 Cologne, Germany

e-mail: sandraklintworth@yahoo.de

E. von Elert

e-mail: evelert@uni-koeln.de increased bacterial degradation of the kairomone. More specifically, we assume that higher algal food concentration is associated with higher bacterial abundances, which degrade the kairomone during the experiment. We tested our hypothesis by treating food algae with antibiotics before providing them as food to Daphnia. Antibiotics reduced bacterial abundances at high and low food concentrations. Reduced bacterial abundances at high food concentrations led to the same level of neckteeth induction as at low food concentrations. A linear regression revealed a significant correlation of neckteeth induction to bacterial abundances. We therefore conclude that differences in neckteeth induction at different food concentrations are not caused by the food quantity effects but by differences in bacterial degradation of the kairomone.

Keywords Food quantity - Bacterial degradation . Kairomone $\cdot$ Inducible defense $\cdot$ Phenotypic plasticity

\section{Introduction}

In freshwater systems, communication is mostly reduced to chemical cues due to conditions like high turbidity or poor light transmission, which make it difficult for animals to rely on visual cues (Brönmark and Hansson 2000). Chemical cues may transmit information about the presence of prey or predators, 
food or mating partners (Brönmark and Hansson 2000). One well investigated model organism in this field of research is Daphnia sp., a herbivorous filterfeeder and important link between trophic levels (Lampert 2006). Daphnia recognizes the presence of predators via chemical cues that are emitted by the predator, so-called kairomones (Diel et al. 2020; Krueger and Dodson 1981; Stibor 1992). Kairomones are semiochemicals that induce responses which are advantageous for the receiver and disadvantageous for the emitter. Although many cases of information conveyance by kairomones are known, the chemical identity of kairomones themselves has been uncovered in only a few of those cases (Hahn et al. 2019; Weiss et al. 2018). Upon recognition of the kairomone, a wide range of inducible defenses can be expressed, which comprise physiological, behavioral, or morphological changes (Lass and Spaak 2003). The expression of those inducible defenses is associated with costs, which trade-off the benefits of a defense in terms of fitness (Hammill et al. 2008). The associated costs are regarded as the cause why those defenses are inducible, because constitutive expression would lead to reduced fitness in the absence of the predator.

In many cases physiological changes in response to kairomones lead to changes in life history (Dodson and Havel 1988; Tollrian 1995b). The effect of food quantity on kairomone-mediated physiological changes might be the most difficult to investigate, because changes in food quantity per se can lead to life-history changes (Vanni and Lampert 1992). Variability introduced by genetic variance (Reznick et al. 2000) as well as the dependence of reaction norms on intrinsic values of traits (Wolinska et al. 2007) further complicates this relation (Cressler et al. 2010). This might be the explanation for the fact that in the presence of predators that select for big prey, like fish or Notonecta sp., some Daphnia only respond to the kairomone at high food concentrations (Dodson 1988; Dodson and Havel 1988), whereas others show enhanced responses under food stress (Pauwels et al. 2010). For predators that select for small prey, like Chaoborus sp., this relation with food quantity gets even more complex, and responses of Daphnia are highly variable (Dodson 1988; Tollrian 1995b). Due to the fact that costs of inducible defenses are measured as life history traits, it is hardly possible to differentiate life-history change as part of the defense from those that represent the cost of the inducible defense.
Behavioral changes as inducible defenses can, amongst others (e.g. Langer et al. (2019)), result in diel vertical or horizontal migration (Dawidowicz and Loose 1992; Kvam and Kleiven 1995; von Elert and Loose 1996). Vertically migrating Daphnia experience lower temperatures in deeper strata, so that the associated costs of migration are reduced somatic growth and reproduction rates (Dawidowicz and Loose 1992). As in nature food availability is decreasing in deeper strata, lower food quantity in the epilimnion leads to a slight decrease in diel vertical migration of D. magna in the presence of fish (Loose and Dawidowicz 1994) or even to a suppression of migration when food quantity is limiting (Beklioglu et al. 2008; Johnsen and Jakobsen 1987).

Morphological defenses comprise a huge variety of alterations in carapace shape like the elongation of head or tail spine, formation of head crests, neckteeth, or helmets (Diel et al. 2020; Dodson 1988; Lass and Spaak 2003; Spaak and Boersma 1997; Tollrian 1993). The effect of food quantity on morphological defenses was investigated in various predator-prey-systems of Daphnia. D. ambigua increased its helmet size with increasing food concentration in the presence of Chaoborus (Hanazato 1991). The same response of increased defense at high food concentrations was observed in D. retrocurva for its increase in head length in the presence of Chaoborus or Notonecta (Dodson 1988). Furthermore, the relative tail spine length of individuals of the D. galeata $\times$ cucullata $\times$ hyalina complex increased significantly at high food concentrations compared to low ones in the presence of fish (Spaak and Boersma 1997).

In our study, we focused on the morphological defense of $D$. pulex against larvae of Chaoborus sp. D. pulex changes its morphology during those juvenile instars, which are most vulnerable to Chaoborus predation (Pastorok 1981; Tollrian 1995a). The formation of neckteeth, which are small protuberances in the neck region of $D$. pulex, reduces predation rates to a great extent (Tollrian 1995a). Interestingly, neckteeth induction is, so far, the only morphological defense reported to be decreasing at high food concentrations (Parejko and Dodson 1991). Associated costs of neckteeth induction were often detected as a delay of reproduction, shorter body lengths at first reproduction or reduced fitness measured as the intrinsic rate of increase (Black and Dodson 1990; Havel and Dodson 1987; Riessen and Sprules 1990). 
Under the assumption that costs of neckteeth induction per se are independent of food availability, neckteeth induction should not be suppressed when food quantity is saturating. Hence the observation of a reduced neckteeth induction at high food levels (Parejko and Dodson 1991) seems not consistent with the concept of costs associated with the induction of these morphological changes.

Considering this conceptual discrepancy, we hypothesized that the effect of food quantity on neckteeth induction is actually caused by differing bacterial abundances: we assumed that with increasing food concentrations higher abundances of (accompanying) bacteria were added, which lead to higher degradation rates of the Chaoborus kairomone at high food concentrations. We tested this hypothesis by treating the food alga Chlamydomonas klinobasis with antibiotics before adding the alga as food for Daphnia pulex. We counted bacterial abundances in the experimental jars, scored neckteeth, which were induced by the Chaoborus kairomone, during the second instar of D. pulex, and performed a linear regression with the two parameters.

\section{Methods}

Cultivation of animals

Prior to the experiments $D$. pulex clone TCO (Colbourne et al. 2011) was kept in aged and aerated tap water at a density of 10-12 individuals per $800 \mathrm{~mL}$ at $19.2 \pm 0.3{ }^{\circ} \mathrm{C}$ and a 16:8 light:dark cycle. Every second day the animals were transferred into fresh medium containing at least $1 \mathrm{mg} \mathrm{C} / \mathrm{L}$ of Chlamydomonas klinobasis strain \#56 (Limnological Institute, University of Constance).

\section{Cultivation of food}

C. klinobasis was grown in $5 \mathrm{~L}$ semi-continuous batch cultures in cyanophycea medium (von Elert and Jüttner 1997) modified with vitamins. For the experiment Chlamydomonas was incubated for different treatments. The control treatment ('Control') contained Chlamydomonas suspension without any further treatment. For the antibiotics treatment ('Antibiotics') 2 times $45 \mathrm{~mL}$ of Chlamydomonas suspension were centrifuged at $3214 \mathrm{~g}$ for $5 \mathrm{~min}$ and the supernatant was discarded. The pellets were each resuspended in $100 \mathrm{~mL}$ cyanophycea medium containing $500 \mu \mathrm{g} / \mathrm{mL}$ ampicillin and $50 \mu \mathrm{g} / \mathrm{mL}$ tetracycline and incubated in sterile Erlenmeyer flasks for $22 \mathrm{~h}$ on a rotary shaker set to $80 \mathrm{rpm}$ at constant light. After incubation, the cultures were centrifuged as above. The pellets were resuspended in fresh cyanophycea medium without antibiotics and centrifuged again to wash the cells. Afterwards, the pellets were resuspended in $100 \mathrm{~mL}$ fresh cyanophycea medium and stored in Erlenmeyer flasks for subsequent use. In order to account for effects of processing the cultures, an additional control treatment for centrifugation and incubation on the rotary shaker was established ('Shaker'). All food suspensions were screened using a $30 \mu \mathrm{m}$ gauze, which had been inserted in the cap of a bottomless Nalgene bottle, that was used as a funnel. The volume of the food suspension that was needed was determined photometrically at a wavelength of $470 \mathrm{~nm}$ by using a calibration curve relating the carbon content to the optical density.

\section{Preparation of Chaoborus incubation water extract}

The extract of Chaoborus incubation water was prepared as according to Klintworth and von Elert (2020). Approximately 300-350 fourth instar larvae (ordered from www.interaquaristik.de) of Chaoborus flavicans were fed with 1-2 neonates of $D$. pulex clone TCO per larva. After 1-2 h of feeding, the larvae were transferred into $1 \mathrm{~L}$ of fresh aged and aerated tap water without any food. After $24 \mathrm{~h}$ the larvae were removed from the water using a $250 \mu \mathrm{m}$ gauze, and the water was filtered through a glass fiber filter (Whatman, MN $85 / 220,0.4 \mu \mathrm{m})$. Subsequently, the kairomone was enriched by solid phase extraction (VARIAN, Bond Elut-C18, $10 \mathrm{~g}$ of sorbent, volume $60 \mathrm{~mL}$, Agilent Technologies) as according to Christjani et al. (2016). The eluates were pooled and evaporated to dryness in a rotary evaporator and a vacuum centrifuge. The dried residues were dissolved in $58 \mu \mathrm{L}$ methanol and stored at $-20{ }^{\circ} \mathrm{C}$ until use. A control extract was prepared in exactly the same way but without any animals in the water.

\section{Experimental setup}

A cohort of synchronized animals that had just released their first eggs into the brood chamber was 
distributed to the different food level treatments, containing either $0.5 \mathrm{mg} \mathrm{C} / \mathrm{L}$ or $1.5 \mathrm{mg} \mathrm{C} / \mathrm{L}$ of $C$. klinobasis. Subsequently, the treatments are referred to as 'low food' and 'high food'. When the animals had deposited their second clutch into the brood chamber, they were divided into the food treatments control ('Control'), control of the rotary shaker ('Shaker') and the antibiotics treatment ('Antibiotics'). For details on the preparation of those treatments see 'Cultivation of food'. For each of these food treatments, there was a control treatment and a kairomone treatment. The kairomone treatment contained $1.5 \mu \mathrm{L}$ of the Chaoborus incubation water extract per $150 \mathrm{~mL}$. This volume of extract had induced an intermediate degree of neckteeth induction during a dose response experiment of $D$. pulex clone TCO (same conditions as for the cultivation). The control treatment contained the same volume of control extract. Each treatment was replicated fivefold.

The animals carrying their second clutch in the brood chamber were kept individually in $150 \mathrm{~mL}$ aged and aerated tap water containing either $0.5 \mathrm{mg} \mathrm{C} / \mathrm{L}$ or $1.5 \mathrm{mg} \mathrm{C} / \mathrm{L}$ of $C$. klinobasis of the respective food treatment combined with either the control extract or the extract of the Chaoborus incubation water extract. After the second clutch had hatched, mothers were removed from the jars, and neonates were removed so that no more than 6 experimental neonates remained in the jars, as neckteeth induction was shown to be affected by the density of conspecifics (Tollrian et al. 2015). Neonates that were removed were pooled per treatment, and their dry mass was determined in subsamples of 2 times 10 neonates per treatment. Those dry masses were later on used as $\mathrm{w}_{0}$ for the calculation of the somatic growth rates. The experimental animals were transferred daily to freshly prepared jars. After transferring the animals, a sample of $8 \mathrm{~mL}$ was taken from each jar that had contained animals in their first instar to quantify the abundance of bacteria. For details on fixing, staining, and counting the bacteria see 'Bacteria counting'. Neckteeth induction of 5 experimental animals per jar was determined during their second juvenile instar using the method developed by Tollrian (1993) with the slight modification that each tooth was scored with $10 \%$ and no differentiation was made between big and small teeth as described in Schwarzenberger et al. (2014). After the animals had deposited their first clutch into their brood chambers, the clutch size was determined under a binocular microscope and three egg-bearing animals per jar were taken for the determination of their dry mass $\left(\mathrm{w}_{\mathrm{t}}\right)$. The time until maturity was determined and the somatic growth rates $(g)$ were calculated according to the following formula: $g=\left(\ln \left(\mathrm{w}_{\mathrm{t}}\right)-\ln \left(\mathrm{w}_{0}\right)\right) / \mathrm{t}$, with $w_{\mathrm{t}}$ being the individual weight at day $\mathrm{t}$ and $w_{0}$ being the individual weight at day 0 (Rothhaupt and Lampert 1992). Since we were not interested in any resource allocation effects, but only in any physiological effects of the antibiotics on the animals, we did not dissect the eggs from the mothers. Furthermore, including the eggs during the dry weight determination makes $g$ a better predictor for fitness than growth rates calculated from dry weights excluding the egg masses (Lampert and Trubetskova 1996).

\section{Bacteria counting}

The samples were immediately fixed in $4 \%$ sugarformol. The bacteria in the samples were stained using DAPI (4',6-Diamidin-2-phenylindol). The filtration device was rinsed with deionized water and the required volume of the sample was filtered $(0.2 \mu \mathrm{m}$ pore size, $25 \mathrm{~mm} \varnothing$, Whatman Nuclepore Polycarbonate Membrane) to reach the appropriate density of bacteria on the filter. The filter with the sample on it was rinsed with deionized water and $300 \mu \mathrm{L}$ of $5 \mu \mathrm{g} /$ mL DAPI were put on the filter. During the incubation time of $5 \mathrm{~min}$ the filters were covered. Subsequently, the DAPI was removed and the filters were rinsed with deionized water again. Bacteria were counted immediately after staining under a fluorescence microscope (ZEISS Axioskop equipped with Shutter HXP 120) using $100 \times$ magnification. The abundance of bacteria on the filter was calculated by counting 20 randomly selected fields per filter ( 1 field $\hat{=}$ $\left.15,625 \mu \mathrm{m}^{2}\right)$. One filter per experimental replicate was prepared ( $n=5$ per treatment).

\section{Statistical analyses}

All statistical analyses were performed in RStudio version 1.1.423 $(\mathrm{R}$ version $\times 64$ 3.4.3). In case a parameter was determined on more than 1 animal per replicate, the average of those values per replicate was calculated and used for statistics. Data were checked for homoscedasticity, and, if given, an ANOVA type 2 
followed by Tukey's HSD test was performed. If not given, a Kruskal-Wallis rank sum test was performed. Data were checked for normal distribution, but an ANOVA was performed either way, as the ANOVA remains a valid statistical procedure under nonnormality, as long as the assumption of homoscedasticity is met (Blanca et al. 2017). In cases of unequal sample sizes, an ANOVA type 3 followed by a GamesHowell test was performed. Spearman's rank correlation was used for the correlation of neckteeth induction and bacteria abundances. The significance level for all analyses was $p<0.05$.

\section{Results}

All Daphnia that grew in the chemical absence of Chaoborus did not express any neckteeth and were excluded from statistical analyses. In the chemical presence of Chaoborus neckteeth induction was affected by the food concentration and the treatment of the food (Table 1). No interaction between treatment of the food and food concentration was found. Neckteeth induction in the Control food treatment was significantly different at the two food concentrations (Fig. 1). On low food neckteeth induction was 63 $( \pm 4) \%$ (mean $\pm \mathrm{SD}$ ), whereas on high food neckteeth induction was only $42( \pm 11) \%$. This reduction in neckteeth induction on high food was not found in the Shaker or the Antibiotics treatment. In the Shaker treatment neckteeth induction was $62( \pm 9) \%$ on low food and $52( \pm 7) \%$ on high food. In the Antibiotics treatment neckteeth induction was $75( \pm 6) \%$ on low food and $71( \pm 6) \%$ on high food. Neckteeth induction on high food in the Antibiotics treatment was significantly higher than in the Control and the

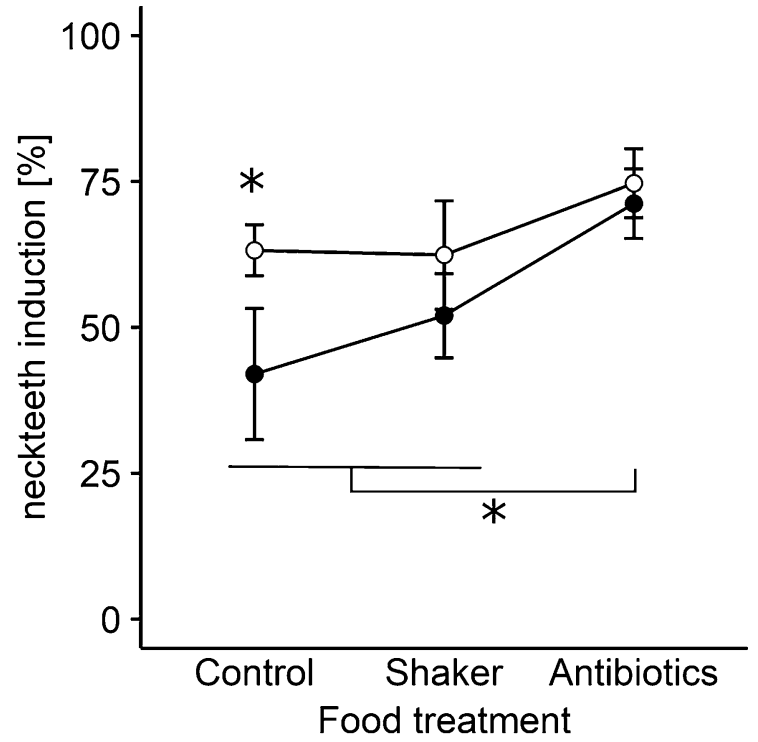

Fig. 1 Mean \pm SD of neckteeth induction [\%] of D. pulex growing on $C$. klinobasis that had either been cultured under control conditions (Control) or incubated on a rotary shaker for $22 \mathrm{~h}$ (Shaker) or incubated on a rotary shaker in antibioticcontaining medium (Antibiotics). D. pulex was either grown under high food conditions $(-1.5 \mathrm{mg} \mathrm{POC} / \mathrm{L})$ or low food conditions $(\bigcirc ; 0.5 \mathrm{mg}$ POC/L). Only data from $D$. pulex grown in the chemical presence of Chaoborus are presented. Neckteeth induction in the chemical absence of Chaoborus was $0 \%$ in all treatments. Asterisks associated to brackets represent significant differences within the same food concentration, whereas single asterisks indicate significant differences within the same food treatment (two way ANOVA type 2 followed by Tukey's HSD test). Details on the statistical analysis can be found in Table 1

Shaker treatment and was not significantly different from the neckteeth induction on low food.

Bacterial abundances were also affected by both the food concentration and the treatment of the food (Table 2). A significant difference in bacterial abundances between food concentrations was only found in the Control treatment (Fig. 2). At low food only 2.2

Table 1 Results of a two-way ANOVA type 2 for the analysis of the neckteeth induction (see Fig. 1)

\begin{tabular}{lccccc}
\hline & Df & Sum Sq & Mean Sq & $F$-value & $p$-value \\
\hline Food concentration & 1 & 1027 & 1027 & 17.39 & $\mathbf{0 . 0 0 0 3}$ \\
Treatment & 2 & 2278 & 1139 & 19.29 & $\mathbf{1 . 0 e}-\mathbf{0 5}$ \\
Food conc. $\times$ Treatment & 2 & 398 & 199 & 3.37 & 0.051 \\
Residuals & 24 & 1417 & 59 & \\
\hline
\end{tabular}

Only data of the treatments containing Chaoborus incubation water extract were included in the analysis. Significant $p$-values are indicated in bold 
Table 2 Results of a two-way ANOVA type 2 for the analysis of the bacterial abundance (see Fig. 2)

\begin{tabular}{lccccc}
\hline & Df & Sum Sq & Mean Sq & $F$-value & $p$-value \\
\hline Food concentration & 1 & $4.67 \mathrm{e}+10$ & $4.67 \mathrm{e}+10$ & 18.11 & $\mathbf{0 . 0 0 0 2}$ \\
Treatment & 2 & $2.62 \mathrm{e}+11$ & $1.31 \mathrm{e}+11$ & 50.80 & $\mathbf{2 . 3 e - 0 9}$ \\
Food conc. $\times$ Treatment & 2 & $1.29 \mathrm{e}+10$ & $6.45 \mathrm{e}+09$ & 2.50 & 0.10 \\
Residuals & 24 & $6.18 \mathrm{e}+10$ & $2.57 \mathrm{e}+09$ & \\
\hline
\end{tabular}

Only data of the treatments containing Chaoborus incubation water extract were included in the analysis. Significant $p$-values are indicated in bold

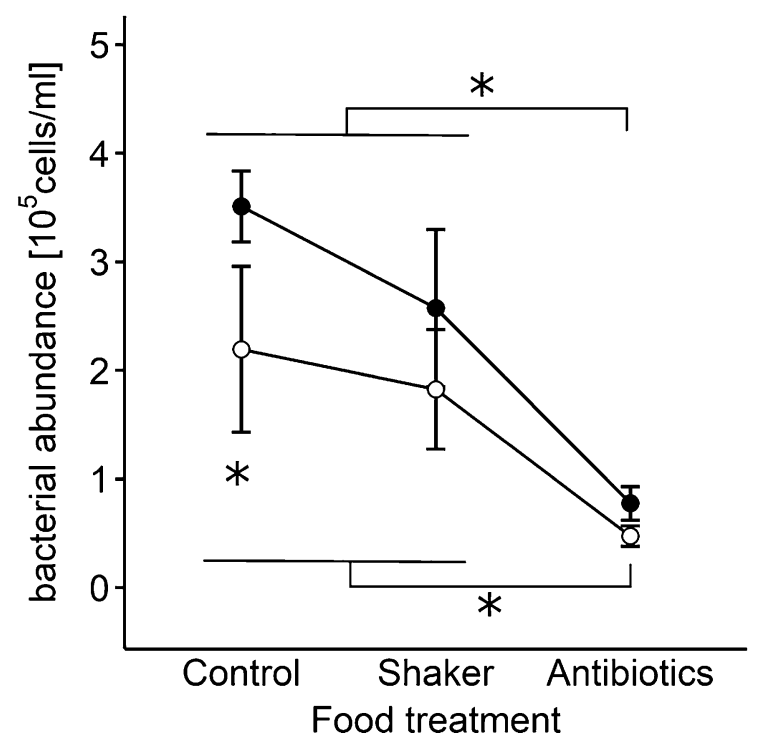

Fig. 2 Mean \pm SD of bacterial abundances $\left[10^{5}\right.$ cells $\left./ \mathrm{ml}\right]$ in the jars of D. pulex growing on C. klinobasis after $22 \mathrm{~h}$. $C$. klinobasis had either been cultured under control conditions (Control) or incubated on a rotary shaker for $22 \mathrm{~h}$ (Shaker) or incubated on a rotary shaker in antibiotic-containing medium (Antibiotics). D. pulex was either grown under high food conditions $(1.5 \mathrm{mg}$ POC/L) or low food conditions $(\bigcirc$; $0.5 \mathrm{mg}$ POC/L). Only data from jars containing D. pulex grown in the chemical presence of Chaoborus are presented. Asterisks associated to brackets represent significant differences within the same food concentration, whereas single asterisks indicate significant differences within the same food treatment (two way ANOVA type 2 followed by Tukey's HSD test). Details on the statistical analysis can be found in Table 2

$( \pm 0.8) \cdot 10^{5}$ cells $/ \mathrm{mL}$ were counted, whereas at high food $3.5( \pm 0.3) \cdot 10^{5}$ cells $/ \mathrm{mL}$ were counted. In the Shaker treatment bacterial abundances were slightly but not significantly reduced to $1.8( \pm 0.6) \cdot 10^{5}$ cells/ $\mathrm{mL}$ at low food compared to $2.6( \pm 0.7) \cdot 10^{5}$ cells $/ \mathrm{mL}$ at high food. Antibiotics significantly decreased the abundance of bacteria to $0.5( \pm 0.1) \cdot 10^{5}$ cells $/ \mathrm{mL}$ and

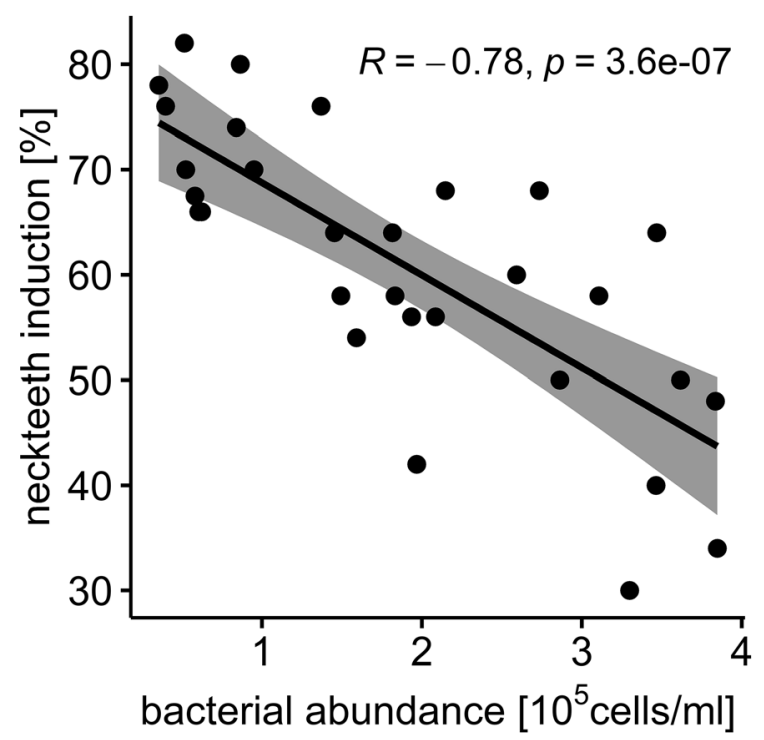

Fig. 3 Neckteeth induction [\%] in D. pulex as a function of bacterial abundance $\left[10^{5}\right.$ cells $\left./ \mathrm{ml}\right]$ after $22 \mathrm{~h}$. Points represent single replicates. Only data from jars containing $D$. pulex grown in the chemical presence of Chaoborus are presented. The black line indicates a linear regression with $95 \%$ confidence interval (Spearman's rank correlation: rho $=-0.78 ; p=3.6^{*} 10^{-7}$ )

$0.8( \pm 0.2) \cdot 10^{5}$ cells $/ \mathrm{mL}$ at low food and high food, respectively.

In order to test if neckteeth induction would decrease with the abundance of bacteria, we correlated the neckteeth induction to the bacterial abundances and performed a linear regression (Fig. 3). Spearman's rank correlation revealed a significant negative correlation (rho $=-0.78 ; p=3.6 * 10^{-7}$ ) with neckteeth induction decreasing with increasing bacterial abundances.

The analysis of clutch size and somatic growth rates revealed that a lower food concentration reduced both parameters, whereas the presence neither of antibiotics nor of the kairomone had an effect (Fig. S1, S2, 
Table S1, S2). The analysis of the time to maturity revealed that there were no significant differences between treatments (Fig. S3, Table S3).

\section{Discussion}

We found that neckteeth induction decreased with increasing abundances of bacteria. Bacterial abundances were reduced by treating the algae suspensions with antibiotics before the algae were provided as food for Daphnia. The reduction of bacteria was significant both at low and high food concentrations, and reduced bacterial abundances at high food led to the same level of neckteeth induction as at low food. A linear regression of neckteeth induction to bacterial abundances revealed a significant negative correlation: neckteeth induction decreased with increasing bacterial abundances.

Parejko and Dodson (1991) reported high neckteeth induction at low food and less neckteeth induction at high food, and thus, concluded that neckteeth induction is influenced by food quantity. Although they had chosen more extreme food concentrations (0.31 mg C/L and $15.3 \mathrm{mg} \mathrm{C/L}$ for low and high food, respectively), we as well found less neckteeth induction at high food in the Control food treatment, and therewith corroborate the findings of Parejko and Dodson (1991). Due to an additional treatment of the food suspension with antibiotics we here revealed that this decrease in neckteeth induction at high food is related to the high abundance of bacteria. In our experiments increasing experimental food concentrations were obtained by diluting increasing aliquots of the same stock food suspension. Since the food suspension was not bacteria free, addition of different aliquots of this suspension did not only result in low and high algal concentrations but as well in low and high bacterial abundances. Although no bacterial abundances are reported by Parejko and Dodson (1991) it is reasonable to assume that in their experiments high and low food concentrations as well were related to high and low bacterial abundances, since their food alga was not explicitly cultured axenically and since the different food concentrations supposedly were as well prepared from the same stock suspension.

We hypothesized that higher bacterial abundances result in higher degradation rates. By treating the food suspensions with antibiotics, this treatment contained reduced bacterial abundances and initially identical kairomone concentrations. Due to the fact that at high food concentrations the neckteeth induction was significantly lower in the Antibiotics than in the Control treatment, we conclude that kairomone concentrations, in line with higher bacterial abundances, most probably decreased at higher rates in the Control than in the Antibiotics treatment. Therefore, our results clearly demonstrate that food quantity does not affect neckteeth induction as long as food concentrations are not limiting. This conclusion is in line with a study, in which a flow-through system was used to determine food quantity effects on neckteeth induction (Tollrian 1995b). In that setup a continuous input of the kairomone, and thus, a constant concentration of the kairomone, was assured. Therefore, no difference in neckteeth induction on different food concentrations was observed.

The kairomone produced by Chaoborus was identified as a group of fatty acid-amino acid conjugates, which are made up of a glutamine head group and long chain fatty acids conjugated to the $\alpha$-amino group of glutamine (Weiss et al. 2018). The fact that glutamine lipids themselves can be incorporated in bacterial cell membranes (Zhang et al. 2009) makes it very likely that the kairomone is degradable by bacteria and that bacteria use such conjugates as sources for those molecules.

The expression of inducible defenses can be considered adaptive as long as the degree of expression of the defense is linked to the real predation risk. Since inducible defenses are associated with costs, expression of such defenses in the absence of predators would bear costs without any benefits. It is therefore highly adaptive to link the expression of inducible defenses to chemical cues that reliably indicate the risk of predation. Hence, from an evolutionary perspective, kairomones must reliably signal not only the presence of a predator but as well predator abundances or predator activities. Accordingly, higher predator densities result in stronger expression of defenses, for example in increased amplitudes of diel vertical migration (von Elert and Pohnert 2000), in a decreased size at first reproduction (von Elert and Stibor 2006) or stronger expression of a morphological defense (Tollrian 1993).

In order to be considered reliable cues for predator densities, kairomones dissolved in water should be 
subjected to a certain turnover, so prey can also perceive declining predation risk. One way of turnover or removal is bacterial degradation. The effect of bacterial degradation of a kairomone on an inducible defense of Daphnia was already shown for the kairomone produced by fish (Loose et al. 1993). After incubating the non-sterile fish incubation water for $24 \mathrm{~h}$ at $37^{\circ} \mathrm{C}$, D. magna did not respond to the fish incubation water by performing diel vertical migration, whereas fish incubation water that was incubated in the absence of bacteria remained active. Furthermore, incubation of fish incubation water at $4{ }^{\circ} \mathrm{C}$ under otherwise identical conditions did not lead to a loss of activity and it still induced diel vertical migration in D. magna. The kairomone produced by fish is the bile salt $5 \alpha$-cyprinol-sulphate (Hahn et al. 2019). Bacteria are known to be involved in synthesis pathways of bile salts (Hofmann and Hagey 1998), and also in the degradation of bile salts (Philipp 2011). Another study on the bacterial degradation of the fish kairomone provided further evidence that the amplitude of diel vertical migration of D. magna is dependent on bacterial abundances (Beklioglu et al. 2006).

We here assured that Daphnia would not be affected by the antibiotics treatment of the food algae by washing the algae with medium free of antibiotics prior to feeding them to the daphnids. It has been reported that antibiotics may negatively affect growth rates or clutch sizes in Daphnia (Kim et al. 2012; Wollenberger et al. 2000). However, we detected neither of those effects, which makes it highly improbable that in the antibiotics treatment any direct effect of the antibiotics on Daphnia occurred. Accordingly, the effects of food quantity on somatic growth rate or clutch size that we observed here are in accordance with the well-known effects of food quantity on these parameters (Lampert and Trubetskova 1996; Vanni and Lampert 1992).

Furthermore, we detected no apparent costs of neckteeth induction in our study. Clutch sizes, somatic growth rates, and the time until maturity were not affected by the kairomone treatment. Especially the time until maturity was considered a cost of neckteeth induction (Black and Dodson 1990; Havel and Dodson 1987), which could be also caused by changes in lifehistory. More recent studies, however, found no costs of neckteeth induction (Riessen 2012; Tollrian 1995b). Tollrian (1995b) disentangled the effects of life-history change and costs of morphological defense by restricting the kairomone exposure of Daphnia to the developmental times when the respective defense is expressed and found no life-history shifts in the treatments, in which neckteeth were induced. Riessen (2012) performed life-history experiments with 2 clones that differed in their degree of neckteeth formation, but found the same degree of life-history shifts, which, assuming neckteeth induction would entail costs, should have also differed. As neckteeth induction does not seem to have any apparent costs that would affect life-history or fitness of Daphnia, it might be maladaptive that this morphological defense would be affected by the availability of resources.

From our study we conclude that the food quantity effects on neckteeth induction that have been reported before (Parejko and Dodson 1991) were most probably caused by differences in bacterial abundances and bacterial degradation rates of the kairomone in the experimental setup. We largely excluded the effect of bacterial degradation of the kairomone in our study, and we were able to show that differences in neckteeth induction between food concentrations, as they were detected in the Control, were not detected in the treatment, in which bacterial degradation was reduced. The inducible morphological defense of $D$. pulex against Chaoborus does not only include the formation of neckteeth, but comprises further morphological changes as a stiffening (Laforsch et al. 2004) and thickening (Kruppert et al. 2017) of the carapace. This has been corroborated by the finding that Chaoborus incubation water extract induces an upregulation of chitin deacetylase genes in D. pulex (Christjani et al. 2016). Although we focused solely on neckteeth induction in this study, we assume that further morphological changes like the thickening of the carapace are as well not affected by food concentration in D. pulex.

Acknowledgments We thank Prof. Dr. Hartmut Arndt for the provision of resources for bacteria staining and counting.

Author contributions Sandra Klintworth \& Eric von Elert contributed to conceptualization; Sandra Klintworth contributed to methodology; Sandra Klintworth was involved in formal analysis and investigation; Sandra Klintworth contributed to writing — original draft preparation; Sandra Klintworth \& Eric von Elert contributed to writing-review and editing; There was no funding acquisition; Eric von Elert provided the resources; Eric von Elert contributed to supervision. 
Funding Open Access funding enabled and organized by Projekt DEAL.

\section{Compliance with ethical standards}

Conflict of interest The authors declare that they have no conflict of interest.

Open Access This article is licensed under a Creative Commons Attribution 4.0 International License, which permits use, sharing, adaptation, distribution and reproduction in any medium or format, as long as you give appropriate credit to the original author(s) and the source, provide a link to the Creative Commons licence, and indicate if changes were made. The images or other third party material in this article are included in the article's Creative Commons licence, unless indicated otherwise in a credit line to the material. If material is not included in the article's Creative Commons licence and your intended use is not permitted by statutory regulation or exceeds the permitted use, you will need to obtain permission directly from the copyright holder. To view a copy of this licence, visit http://creativecommons.org/licenses/by/4.0/.

\section{References}

Beklioglu M, Cetin AG, Zorlu P, Ay-Zog D (2006) Role of planktonic bacteria in biodegradation of fish-exuded kairomone in laboratory bioassays of diel vertical migration. Arch Hydrobiol 165:89-104. https://doi.org/10.1127/ 0003-9136/2006/0165-0089

Beklioglu M, Gozen AG, Yıldırım F, Zorlu P, Onde S (2008) Impact of food concentration on diel vertical migration behaviour of Daphnia pulex under fish predation risk. Hydrobiologia 614:321-327. https://doi.org/10.1007/ s10750-008-9516-8

Black AR, Dodson SI (1990) Demographic costs of Chaoborusinduced phenotypic plasticity in Daphnia pulex. Oecologia 83:117-122. https://doi.org/10.1007/BF00324642

Blanca MJ, Alarcón R, Arnau J, Bono R, Bendayan R (2017) Non-normal data: is ANOVA still a valid option? Psicothema 29:552-557. https://doi.org/10.7334/ psicothema2016.383

Brönmark C, Hansson L-A (2000) Chemical communication in aquatic systems: an introduction. Oikos 88:103-109. https://doi.org/10.1034/j.1600-0706.2000.880112.x

Christjani M, Fink P, von Elert E (2016) Phenotypic plasticity in three Daphnia genotypes in response to predator kairomone: evidence for an involvement of chitin deacetylases. J Exp Biol 219:1697-1704. https://doi.org/10.1242/jeb. 133504

Colbourne JK, Pfrender ME, Gilbert D, Thomas WK, Tucker A, Oakley TH, Tokishita S, Aerts A, Arnold GJ, Basu MK, Bauer DJ, Cáceres CE, Carmel L, Casola C, Choi J-H, Detter JC, Dong Q, Dusheyko S, Eads BD, Fröhlich T, Geiler-Samerotte KA, Gerlach D, Hatcher P, Jogdeo S, Krijgsveld J, Kriventseva EV, Kültz D, Laforsch C, Lindquist E, Lopez J, Manak JR, Muller J, Pangilinan J,
Patwardhan RP, Pitluck S, Pritham EJ, Rechtsteiner A, Rho M, Rogozin IB, Sakarya O, Salamov A, Schaack S, Shapiro H, Shiga Y, Skalitzky C, Smith Z, Souvorov A, Sung W, Tang Z, Tsuchiya D, Tu H, Vos H, Wang M, Wolf YI, Yamagata H, Yamada T, Ye Y, Shaw JR, Andrews J, Crease TJ, Tang H, Lucas SM, Robertson HM, Bork P, Koonin EV, Zdobnov EM, Grigoriev IV, Lynch M, Boore JL (2011) The ecoresponsive genome of Daphnia pulex. Science 331:555-561. https://doi.org/10.1126/science. 1197761

Cressler CE, King AA, Werner EE (2010) Interactions between behavioral and life-history trade-offs in the evolution of integrated predator-defense plasticity. Am Nat 176:276-288. https://doi.org/10.1086/655425

Dawidowicz P, Loose CJ (1992) Metabolic costs during predator-induced dielvertical migration of Daphnia. Limnol Oceanogr 37:1589-1595. https://doi.org/10.4319/lo. 1992.37.8.1589

Diel P, Kiene M, Martin-Creuzburg D, Laforsch C (2020) Knowing the enemy: inducible defences in freshwater zooplankton. Diversity 12:147. https://doi.org/10.3390/ d12040147

Dodson SI (1988) Cyclomorphosis in Daphnia galeata mendotae birge and D. retrocurva forbes as a predator-induced response. Freshw Biol 19:109-114. https://doi.org/10. 1111/j.1365-2427.1988.tb00332.x

Dodson SI, Havel JE (1988) Indirect prey effects: some morphological and life history responses of Daphnia pulex exposed to Notonecta undulata. Limnol Oceanogr 33:1274-1285. https://doi.org/10.4319/lo.1988.33.6.1274

Hahn MA, Effertz C, Bigler L, von Elert E (2019) 5 $\alpha$-cyprinol sulfate, a bile salt from fish, induces diel vertical migration in Daphnia. Elife. https://doi.org/10.7554/eLife.44791

Hammill E, Rogers A, Beckerman AP (2008) Costs, benefits and the evolution of inducible defences: a case study with Daphnia pulex. J Evol Biol 21:705-715. https://doi.org/10. 1111/j.1420-9101.2008.01520.x

Hanazato T (1991) Influence of food density on the effects of a Chaoborus-released chemical on Daphnia ambigua. Freshw Biol 25:477-483. https://doi.org/10.1111/j.13652427.1991.tb01390.x

Havel JE, Dodson SI (1987) Reproductive costs of Chaoborusinduced polymorphism in Daphnia pulex. Hydrobiologia 150:273-281. https://doi.org/10.1007/BF00008708

Hofmann AF, Hagey LR (1998) Bile acids and intestinal bacteria: peaceful coexistence versus deadly warfare. In: Blum HE, Bode C, Bode JC, Santor RB (eds) Gut and the Liver. Kluwer Academic Publisher, Dordrecht, pp 85-103

Johnsen GH, Jakobsen PJ (1987) The effect of food limitation on vertical migration in Daphnia longispina. Limnol Oceanogr 32:873-880. https://doi.org/10.4319/lo.1987.32.4. 0873

Kim HY, Lee MJ, Yu SH, Kim SD (2012) The individual and population effects of tetracycline on Daphnia magna in multigenerational exposure. Ecotoxicology 21:993-1002. https://doi.org/10.1007/s10646-012-0853-z

Klintworth S, von Elert E (2020) Risk of predation alters resource allocation in Daphnia under food limitation. J Plankton Res 42:45-56. https://doi.org/10.1093/plankt/ fbz074 
Krueger DA, Dodson SI (1981) Embryological induction and predation ecology in Daphnia pulex. Limnol Oceanogr 26:219-223. https://doi.org/10.4319/lo.1981.26.2.0219

Kruppert S, Horstmann M, Weiss LC, Witzel U, Schaber CF, Gorb SN, Tollrian R (2017) Biomechanical properties of predator-induced body armour in the freshwater crustacean Daphnia. Sci Rep 7:9750. https://doi.org/10.1038/s41598017-09649-5

Kvam OV, Kleiven OT (1995) Diel horizontal migration and swarm formation in Daphnia in response to Chaoborus. In: Larsson P, Weider LJ (eds) Cladocera as model organisms in biology. Springer, Netherlands, Dordrecht, pp 177-184

Laforsch C, Ngwa W, Grill W, Tollrian R (2004) An acoustic microscopy technique reveals hidden morphological defenses in Daphnia. Proc Natl Acad Sci U S A 101:15911-15914. https://doi.org/10.1073/pnas. 0404860101

Lampert W (2006) Daphnia: model herbivore, predator and prey. Pol J Ecol 54:607-620

Lampert W, Trubetskova I (1996) Juvenile growth rate as a measure of fitness in Daphnia. Funct Ecol 10:631. https:// doi.org/10.2307/2390173

Langer SM, Weiss LC, Ekvall MT, Bianco G, Hansson L-A, Tollrian R (2019) A three-dimensional perspective of Daphnia's swimming behavior with and without predator cues. Limnol Oceanogr 64:1515-1525. https://doi.org/10. 1002/Ino.11132

Lass S, Spaak P (2003) Chemically induced anti-predator defences in plankton: a review. Hydrobiologia 491:221-239. https://doi.org/10.1023/A:1024487804497

Loose CJ, Dawidowicz P (1994) Trade-offs in diel vertical migration by zooplankton: the costs of predator avoidance. Ecology 75:2255. https://doi.org/10.2307/1940881

Loose CJ, von Elert E, Dawidowicz P (1993) Chemically-induced diel vertical migration in Daphnia: a new bioassay for kairomones exuded by fish. Arch Hydrobiol 126:329-337

Parejko K, Dodson SI (1991) The evolutionary ecology of an antipredator reaction norm: Daphnia pulex and Chaoborus americanus. Evolution 45:1665-1674. https://doi.org/10. 1111/j.1558-5646.1991.tb02671.x

Pastorok RA (1981) Prey vulnerability and size selection by Chaoborus Larvae. Ecology 62:1311-1324. https://doi. org/10.2307/1937295

Pauwels K, Stoks R, de Meester L (2010) Enhanced antipredator defence in the presence of food stress in the water flea Daphnia magna. Funct Ecol 24:322-329. https://doi. org/10.1111/j.1365-2435.2009.01641.x

Philipp B (2011) Bacterial degradation of bile salts. Appl Microbiol Biotechnol 89:903-915. https://doi.org/10. 1007/s00253-010-2998-0

Reznick D, Nunney L, Tessier A (2000) Big houses, big cars, superfleas and the costs of reproduction. Trends Ecol Evol 15:421-425. https://doi.org/10.1016/S01695347(00)01941-8

Riessen HP (2012) Costs of predator-induced morphological defences in Daphnia. Freshw Biol 57:1422-1433. https:// doi.org/10.1111/j.1365-2427.2012.02805.x

Riessen HP, Sprules WG (1990) Demographic costs of antipredator defenses in Daphnia Pulex. Ecology 71:1536-1546. https://doi.org/10.2307/1938290
Rothhaupt KO, Lampert W (1992) Growth-rate dependent feeding rates in Daphnia pulicaria and Brachionus rubens: adaptation to intermediate time-scale variations in food abundance. J Plankton Res 14:737-751. https://doi.org/10. 1093/plankt/14.5.737

Schwarzenberger A, Christjani M, Wacker A (2014) Longevity of Daphnia and the attenuation of stress responses by melatonin. BMC Physiol 14:1-7. https://doi.org/10.1186/ s12899-014-0008-y

Spaak P, Boersma M (1997) Tail spine length in the Daphnia galeata complex: costs and benefits of induction by fish. Aquat Ecol 31:89-98. https://doi.org/10.1023/A: 1009935100804

Stibor H (1992) Predator induced life-history shifts in a freshwater cladoceran. Oecologia 92:162-165. https://doi.org/ 10.1007/BF00317358

Tollrian R (1993) Neckteeth formation in Daphnia pulex as an example of continuous phenotypic plasticity: morphological effects of Chaoborus kairomone concentration and their quantification. J Plankton Res 15:1309-1318. https:// doi.org/10.1093/plankt/15.11.1309

Tollrian R (1995a) Chaoborus crystallinus predation on Daphnia pulex: can induced morphological changes balance effects of body size on vulnerability? Oecologia 101:151-155. https://doi.org/10.1007/BF00317278

Tollrian R (1995b) Predator-induced morphological defenses: costs, life history shifts, and maternal effects in Daphnia Pulex. Ecology 76:1691-1705. https://doi.org/10.2307/ 1940703

Tollrian R, Duggen S, Weiss LC, Laforsch C, Kopp M (2015) Density-dependent adjustment of inducible defenses. Sci Rep 5:12736. https://doi.org/10.1038/srep12736

Vanni MJ, Lampert W (1992) Food quality effects on life history traits and fitness in the generalist herbivore Daphnia. Oecologia 92:48-57. https://doi.org/10.1007/BF00317261

von Elert E, Jüttner F (1997) Phosphorus limitation and not light controls the extracellular release of allelopathic compounds by Trichormus doliolum (Cyanobacteria). Limnol Oceanogr 42:1796-1802. https://doi.org/10.4319/lo.1997. 42.8.1796

von Elert E, Loose CJ (1996) Predator-induced diel vertical migration in Daphnia: enrichment and preliminary chemical characterization of a kairomone exuded by fish. J Chem Ecol 22:885-895. https://doi.org/10.1007/ BF02029942

von Elert E, Pohnert G (2000) Predator specificity of kairomones in diel vertical migration of Daphnia: a chemical approach. Oikos 88:119-128. https://doi.org/10.1034/j. 1600-0706.2000.880114.x

von Elert E, Stibor H (2006) Predator-mediated life history shifts in Daphnia: enrichment and preliminary chemical characterisation of a kairomone exuded by fish. Arch Hydrobiol 167:21-35. https://doi.org/10.1127/0003-9136/ 2006/0167-0021

Weiss LC, Albada B, Becker SM, Meckelmann SW, Klein J, Meyer M, Schmitz OJ, Sommer U, Leo M, Zagermann J, Metzler-Nolte N, Tollrian R (2018) Identification of Chaoborus kairomone chemicals that induce defences in Daphnia. Nat Chem Biol 14:1133-1139. https://doi.org/ 10.1038/s41589-018-0164-7 
Wolinska J, Löffler A, Spaak P (2007) Taxon-specific reaction norms to predator cues in a hybrid Daphnia complex. Freshw Biol 52:1198-1209. https://doi.org/10.1111/j. 1365-2427.2007.01757.x

Wollenberger L, Halling-Sørensen B, Kusk KO (2000) Acute and chronic toxicity of veterinary antibiotics to Daphnia magna. Chemosphere 40:723-730. https://doi.org/10. 1016/S0045-6535(99)00443-9

Zhang X, Ferguson-Miller SM, Reid GE (2009) Characterization of ornithine and glutamine lipids extracted from cell membranes of Rhodobacter sphaeroides. J Am Soc Mass Spectrom 20:198-212. https://doi.org/10.1016/j.jasms. 2008.08.017

Publisher's Note Springer Nature remains neutral with regard to jurisdictional claims in published maps and institutional affiliations. 